\title{
Indagações e contradições sobre a ocupação do lugar de aluno com deficiência intelectual no cotidiano de uma escola de ensino fundamental pública de periferia
}

\author{
Flávia Faissal de Souza*
}

\begin{abstract}
Resumo
Inseridos no cotidiano de uma escola pública de ensino fundamental no decorrer de um ano letivo e apoiados pelos pressupostos teórico-metodológicos da perspectiva histórico-cultural, trazemos para análise os lugares ocupados por um aluno com deficiência intelectual. A análise dos lugares ocupados por esse aluno nos dá visibilidade analítica das contradições e paradoxos das políticas de educação inclusiva, ao apontar tanto para o movimento do aluno que se indaga sobre lugar histórico marcado pelos impedimentos das pessoas com deficiência, como pelo movimento de ocupar o seu papel de aluno, enquanto sujeito de direito, inserido nos processos de ensino e aprendizagem.

Palavras-chave: Políticas de educação inclusiva; Práticas de educação inclusiva; Pessoa com deficiência.

\section{Inquiries and contradictions about the student with intellectual disabilities occupied places of the in the} daily life of a outskirts public elementary school
\end{abstract}

\begin{abstract}
Inserted into the daily life of a outskirts public elementary school, in the course of a school year and supported by the theoretical-methodological assumptions of the historical-cultural perspective, we bring to analysis the places occupied by a student with intellectual disabilities. The analysis of these occupied places gives us analytical visibility of inclusive education policies contradictions and paradoxes, by pointing both to the student movement that inquiry about historic place marked by impairments of persons with disabilities, as by movement to take your role as a student, as a person under law, inserted in the processes of teaching and learning.

Keywords: Inclusive education policies; Inclusive education practices; Person with disability

\section{Preguntas y contradicciones sobre la ocupación del estudiante con discapacidad intelectual en la vida cotidiana de una escuela primária pública de la periferia}

\section{Resumem}

Inserta en la vida cotidiana de una escuela primária pública, en el transcurso de un año escolar y apoyados em los supuestos teóricos y metodológicos de la perspectiva histórico-cultural, traemos al análisis de los lugares ocupados por un estudiante con discapacidad intelectual. El análisis de los lugares ocupados, nos da visibilidad analítica a las contradicciones y paradojas de las políticas de educación inclusiva, señalando ambos para el movimiento del estudiante que pregunta sobre lo lugar histórico marcado por impedimentos de las personas con discapacidad, cuánto el movimiento para tomar su papel de estudiante, mientras que sujeto de derecho, en los procesos de enseñanza y aprendizaje.

Palabras clave: Políticas de educación inclusiva, Prácticas de educación inclusiva; Persona com discapacidad.

\section{Introdução}

Nas últimas décadas, especificamente no campo da Educação Especial, vivenciamos a proposição de uma política na perspectiva da educação inclusiva que pela primeira vez na história do país, responsabilizou o Estado pela educação de pessoas com deficiência. Mesmo que marcada por paradoxos e contradições desde seus princípios norteadores às formas como foi traduzida no cotidiano das escolas e salas de aula, a proposição de uma política de Estado de garantia à educação pública e gratuita foi um avanço importante no campo da garantia dos direitos das pessoas com deficiência (SEESP/MEC, 2008; BRASIL, 2009).

Das diretrizes traçadas pelo Ministério da Educação (MEC) (SECADI/MEC, 2016; SEESP/MEC, 2004; 2005a; 2005b; 2005c; 2006a; 2006b; 2006c; 2008; 2009, entre outras) é possível afirmar que a educação inclusiva assumida pelo governo brasileiro parte do princípio de que a escola deve criar condições para atender à diversidade e não deve selecionar os alunos, em função de suas diferenças individuais, por apresentaram 
dificuldades e limites no acompanhamento curricular. Na estrutura dessa política, o foco é a matrícula de todos os alunos no ensino regular, atendendo as demandas políticas de universalização da Educação Básica, com apoio do Atendimento Educacional Especializado (AEE) no contra turno escolar (SEESP/MEC, 2008; CNE/CEB/BRASIL, 2009; BRASIL, 2011).

Dos paradoxos e contradições que constituem a proposta do MEC, é possível assumir que a maioria das questões apontadas, em diferentes estudos sob diferentes perspectivas, estão circunscritas às condições de desenvolvimento das políticas da educação básica de uma forma geral, tais como: os princípios idealizados de escola, aluno e sociedade; apagamento dos conflitos históricos e da realidade socioeconômica brasileira e as marcas das imensas desigualdades; a não consideração da realidade histórica do sistema educacional brasileiro; a não escolarização da grande parte dos alunos; precárias condições para o trabalho docente (LAPLANE, 2004; 2006; GARCIA, 2004; 2009; KASSAR, 2011a; 2011b; 2012; PLESTCH, 2010; PRIETO, 2003; 2010; MENDES, 2006a; 2006b; SOUZA, 2013; 2017).

É importante ressaltar que, no rol das contradições, majoritariamente ao longo dos últimos governos entre 2003-2016, vivenciamos a manutenção de políticas educacionais por programas, alinhadas com o movimento de mercantilização e de privatização da educação. Contudo, a política na perspectiva da educação inclusiva, ainda que traga para o Estado a responsabilidade pela educação das pessoas com deficiência e tencione o lugar das instituições filantrópicas em relação ao movimento histórico marcado quase que exclusivamente pelo repasse pelos governos de responsabilidade e de investimento ao setor privada filantrópico, manteve laços com esse setor (SOUZA, 2017).

Nesse cenário político de nosso país, hoje há um aprofundamento no acirramento de disputa de forças, construídas ao logo da história da escolarização das pessoas com deficiência, sobre os rumos da educação especial na perspectiva da educação inclusiva, sustentada pela mais diversa ordem de interesses. De um lado, o movimento social advoga em prol da matrícula de todos os alunos com deficiência, sem exceção, no ensino regular com suporte do AEE. De outro, os representantes das instituições filantrópicas defendem a manutenção da educação desses alunos em instituições especializadas. Se por um lado os argumentos centrais para que todos os alunos com deficiência sem exceção, estejam matriculados no ensino regular, encontram sustentação sobretudo no âmbito dos direitos humanos e de uma concepção de desenvolvimento que defende a diversidade enquanto constitutiva do humano, na qual as diferenças importam nos processos de ensino e aprendizagem; por outro, as instituições filantrópicas ressaltam e se valem de um determinado conhecimento técnico construído ao longo da sua história de responsável pela educação especial em nosso país (SEESP/MEC, 2008; SNPD/SDH/BRASIL, 2010; SECADI/MEC, 2011; JANNUZZI; CAIADO, 2013; BRASIL， 2014; LAPLANE, CAIADO, KASSAR, 2016).

Esse embate, há um tempo ecoa no meio educacional e divide opiniões de educadores e familiares. A fim de problematizarmos as contradições e os paradoxos dessa proposta política, trazemos para este texto algumas ponderações realizadas a partir de uma pesquisa longitudinal realizada em uma escola pública de periferia de ensino fundamental. Apoiadas nos estudos de Ball e Bowe (1992) e Ball (1994; 2001) voltamos nossos olhos para o contexto de prática, das possíveis traduções dos textos políticos. Assumimos ainda que as diretrizes políticas conforme traduzidas nos contextos locais, se materializam nas práticas cotidianas escolares e marcam as condições de desenvolvimento dos sujeitos. Visto que, conforme escreve Vygotski (1934/2010, p.695),

[...] o meio desempenha no desenvolvimento da criança, no que se refere ao desenvolvimento da personalidade e de suas características específicas ao homem, o papel de uma fonte de desenvolvimento, ou seja, o meio, nesse caso, desempenha o papel não de circunstância, mas de fonte de desenvolvimento.

Isto posto, a nossa inserção no cotidiano de uma escola pública de periferia de ensino fundamental se deu ao longo de um ano letivo com o intuito de problematizarmos as condições de desenvolvimento dos alunos com deficiência no interior desta, ressaltando as contradições e os paradoxos entre as propostas políticas da Educação Inclusiva e sua realização.

Como estratégia de pesquisa, valemo-nos da observação com base nos pressupostos da perspectiva histórico-cultural. Segundo Freitas (2003, p.32) neste tipo de observação alteritária: “o pesquisador ao participar do evento observado constitui-se parte dele, mas ao mesmo tempo mantém 
uma posição exotópica que lhe possibilita o encontro com o outro. E é este encontro que ele procura descrever no seu texto, no qual revela outros textos e contextos". Ainda a autora, afirma que esse tipo de pesquisa, "se constitui pois em um encontro de muitas vozes: ao se observar um evento depara-se com diferentes discursos verbais, gestuais e expressivos. São discursos que refletem e refratam a realidade da qual fazem parte construindo uma verdadeira tessitura social" (FREITAS, 2003, p. 33).

Para análise dos registros em videogravação, audiogravação e diário de campo realizados no decorrer da pesquisa, foi fundamental a categoria da contradição. Posto que, para Vygotski (1929/2000; 1931/1995), o movimento e a contradição são categorias fundamentais para a compreensão do desenvolvimento humano. Neste sentido, trazemos Cheptulin (2004, p. 286-287) quando afirma que a contradição é o movimento que produz as formas de existência, pois

\begin{abstract}
Possuindo tendências opostas em seu funcionamento, sua mudança, e seu desenvolvimento, os contrários excluem-se reciprocamente e encontram-se em estado de luta permanente; entretanto, eles não são divergentes e não se destroem mutuamente; existem juntos e não apenas coexistem, mas estão ligados organicamente, interpenetram-se e supõe-se um ao outro, o que equivale dizer que eles são unidos e representam a unidade dos contrários.
\end{abstract}

Deste estudo, trazemos especificamente para análise nesse artigo os lugares ocupados por um aluno com deficiência intelectual no cotidiano da escola, em especial em uma aula planejada para ser de todos e para cada um, que, apontam tanto para os sentidos e significados construídos ao longo da história sobre os impedimentos das pessoa com deficiência como pelo movimento de ocupar o seu papel de aluno, enquanto sujeito de direito, inserido nos processos de ensino e aprendizagem.

\section{Diego: da fuga da sala de aula a ocupação do lugar de aluno $5^{\circ}$ ano ensino fundamental}

\section{Cenário da Pesquisa}

No contexto das políticas de educação especial e inclusiva, a pesquisa foi realizada junto a uma turma de $5^{\circ}$ ano de ensino fundamental, composta por 38 alunos matriculados, sendo que 35 frequentando a escola regularmente. Desses, três alunos com deficiência: um com deficiência auditiva; um com deficiências múltiplas - física, intelectual e sensorial; e, um com deficiência intelectual, Diego ${ }^{1}$. Além desses alunos, essa turma contava em sua formação com 02 não alfabetizados e um grupo de outros 07 alunos com grande defasagem de conhecimento sistematizado em relação ao conteúdo programado para o $5^{\circ}$ ano ${ }^{2}$.

A professora da turma, embora já tivesse trabalhado com alunos com deficiência no decorrer de sua vida docente, nunca participou de formação inicial ou continuada sobre as especificidades no processo de ensino e aprendizagem dos alunos com deficiência ou mesmo sobre educação inclusiva. Este era seu segundo ano com esta turma. E, embora afirmasse constantemente que não diferenciava um aluno de outro e que entendia que todos tinham o direito de estar na escola, não se cansava de nos relatar a intensificação de seu trabalho e seu desconforto em não conseguir atender a todos da forma como acreditava ser apropriada: dar mais atenção aos alunos com deficiência e os com dificuldade de aprendizagem, respeitando as demandas de cada um, em suas individualidades para participação nas práticas cotidianas escolares e sobretudo nos processos de ensino-aprendizagem.

A estrutura para suporte e acompanhamento dos alunos com deficiência, nessa rede de ensino, era diferente das diretrizes do MEC. Nos anos da pesquisa, o professor de Educação Especial podia atuar nos serviços de atendimento educacional especializado, como: escolas regulares, salas de recursos, classe hospitalar, professor referência [atuação no nível central] e atendimentos domiciliares. Sendo que havia professor de Educação Especial na equipe escolar cujo papel era de atuação direta na equipe, tanto com os alunos e a família no processo de ensino e aprendizagem; dando apoio pedagógico e formação sobre inclusão ao restante da equipe pedagógica, subsidiado pelo projeto pedagógico da escola; e ainda, mediava as articulações com os serviços de atendimento especializado de caráter clínico ou pedagógico (SOUZA, 2013).

$\mathrm{Na}$ época, nessa rede de ensino, havia uma escassez de salas de recursos para oferta do AEE, conforme as diretrizes do MEC. Assim, o serviço era oferecido apenas para alunos surdos, tendo como foco o ensino da Língua Brasileira de Sinais (Libras), e alunos com deficiência visual, cujo foco eram o aprendizado do Braille e o trabalho por eles denominados orientação e mobilidade interna e externa. Havia, também, a sala de acessibilidade, para o desenvolvimento e o aprendizado dos meios 
de Comunicação Aumentativa e Alternativa (CAA); nestas não era especificado o tipo de deficiência atendida.

Dos mais de 20 alunos com deficiência matriculados na escola onde a pesquisa aconteceu nenhum estava matriculado no serviço de AEE, tanto pela distância entre a localização das salas de recursos e a moradia dos alunos, quanto pela falta de vagas. Contudo, a escola contava com uma professora de Educação Especial na equipe para atender a todas as demandas de sua função junto a mais de 20 alunos matriculados em 18 salas de aulas distintas (SOUZA, 2013).

Neste cenário, vivenciamos diversas estratégias pedagógicas desenhadas pela professora. Entretanto, devido à grande heterogeneidade de sua turma, normalmente, a professora trabalhava em pequenos grupos com propostas pedagógicas diferenciadas, sempre privilegiando conteúdos que tivessem significado no cotidiano da vida dos alunos, lançando mão de músicas, dramatizações e material de apoio pedagógico para as atividades propostas.

Essa era a estrutura para atendimento educacional do aluno foco desse estudo. Diego tinha diagnóstico de deficiência intelectual. Na época da pesquisa, com 11 anos, apresentava dificuldade de dicção e grande dificuldade em se relacionar com seus pares, não suportava atividades barulhentas ou que fugissem à rotina esperada, delimitava o tempo todo seu espaço e buscava uma rotina constante de atividades de recorte e de colagem. O aluno também demandava atenção individualizada e questionamentos sobre palavras utilizadas que não em seu sentido literal.

\section{Uma aula para todos e para cada um}

Uma aula para todos e para cada um, assim havia sido planejada pela professora. Na proposta da aula, a professora tinha como foco retomar questões que vinha trabalhando nas aulas de ciências, com a problematização sobre o funcionamento dos sistemas do corpo humano; e, nas aulas de português, com a interpretação do texto Os três porquinhos. Para tal, como atividades foram propostas: exercícios de Lian Gong (respiração e conscientização corporal) e a dramatização do texto citado, propondo o ensaio de diferentes formas de se contar a história.

Uma aula planejada de modo a responder à diversidade rompendo, com o que seria considerado um esquema tradicional. $\mathrm{O}$ principal preceito, segundo as diretrizes propostas pelo MEC para a construção de sistemas educacionais inclusivos, é

[...] a capacidade que o docente tem de organizar as situações de ensino de modo a tornar possível personalizar as experiências comuns de aprendizagem, ou seja, chegar ao maior nível possível de interação entre os estudantes e participação de todos nas atividades propostas, sem perder de vista as necessidades concretas de cada um e em particular daqueles com maior risco de exclusão em termos de aprendizagem e participação (SEESP/MEC, 2006c, p. 175).

A professora, de diferentes maneiras, incentivava que os alunos participassem da aula, se preocupando com as especificidades e condições de participação de cada aluno. E, planejou a aula conforme sustentada pelos argumentos do MEC que preconizam a inclusão educacional dos alunos com deficiência. Entretanto, um aluno escapa.

A dramatização do texto Os três porquinhos acontecia com a participação dos alunos ora como atores, ora como espectadores, ora como auxiliares técnicos. Ora eles dramatizavam sob a narrativa de um narrador, ora assumiam as vozes dos personagens da peça. A professora ensinava as várias possibilidades de se dramatizar um texto.

Embora quase todos os alunos estivessem envolvidos com a atividade, um aluno se ausenta da sala: Diego, que pegou todo o seu material e saiu da sala.

Em uma mesa na porta da biblioteca, no pátio da escola, organizou seu espaço para trabalhar: caderno, revistas, estojo, cola e tesoura. Como fazia todos os dias. Ao terminar a arrumação, Diego pegou um lápis e escreveu em seu caderno, $\mathrm{BAB}$, virando-se para a pesquisadora $\mathrm{e}$ falando: Lição!

Em seguida, iniciou as atividades que compõem sua rotina diária: busca na revista de imagens, recorte, colagem no canto esquerdo do caderno, para posterior nomeação com a professora do ensino regular ou com a professora de educação especial da escola, a ser escrita no canto direito. No momento da colagem, sempre a mesma dinâmica, Diego falava a palavra de forma lenta, ressaltando sílaba por sílaba.

No decorrer da atividade, Maria, aluna do $1 \underline{0}$ ano, se aproximou e perguntou para a pesquisadora: 00:01:05 - Maria: Por que ele tá fazendo o negócio aqui e não tá fazendo na sala? 00:01:15 - Pesquisadora: Pergunta para ele! 00:01:16 - Maria dirigiu-se a Diego: Por que você tá fazendo aqui e não tá na sala? 00:01:24 - Diego: A fessora... deixou aqui fora! 00:01:28 - Pesquisadora: A professora deixou você ficar aqui fora; mas, por que você não está na sala? [...] Conta para a Maria! 
00:01:42 - Diego: Num sei!

00:01:43 - Pesquisadora: Não sabe porquê você não quer ficar na sala?

00:01:51 - Maria perguntou para Diego: Por que você não quer ficar na sala?

00:01:53 - Diego: Num qué, não, é... lá tá cheio lá.

(Episódio construído a partir dos registros

Vídeo T5A 19 e Áudio 01, 7.4.2009)³.

A cena aqui narrada mostra uma situação vivida a partir de uma aula planejada para envolver e possibilitar a participação de todos os alunos. Respeito ao tempo e ao espaço de cada aluno na execução das atividades propostas. Diferentes abordagens do conteúdo programático. Dos 35 alunos, 34 participavam entusiasmadamente das atividades. $\mathrm{O}$ aluno com deficiência auditiva cantava, o aluno com deficiências múltiplas participava da peça conduzido em sua cadeira pela própria professora.

Entretanto, Diego sai do espaço da sala de aula com todo o seu material. Ele se desloca: de sentado no centro da roda em sua sala de aula, lugar que ocupava na primeira atividade, para sentado na porta da biblioteca para fazer o que considera lição. Seu deslocamento, a princípio, foge às regras convencionais estabelecidas para a composição de uma aula. Em geral, é desejável que todos os alunos presentes na sala de aula participem das atividades propostas.

Diego se sente autorizado a sair. Aqui se mostra um acordo tácito construído na história das relações: de um lado, o limite das possibilidades docentes diante de suas condições concretas para o acontecimento da aula e das diferentes demandas da turma, que, ao respeitar as condições do aluno, aceita e autoriza sua ausência; de outro, a dificuldade de Diego em sair de uma rotina escolar por ele vivenciada e imaginada. Nas palavras dele: "Num qué, não, é... lá tá cheio lá".

Diego se coloca [é colocado] à margem da sala, das atividades realizadas. Contudo, é nesse e desse lugar que encontra espaço para cumprir, o que para ele parece ser o seu dever de aluno de $5^{\circ}$ ano do Ensino Fundamental. Ali, encontra o espaço para reiteradamente recortar e colar suas imagens, para fazer sua lição.

Ao analisarmos o dossiê individual ${ }^{4}$ desse aluno, é possível afirmar que, na maioria das aulas, ele trabalhava sozinho. A professora do ensino regular, com o passar do ano, sempre reclamava conosco da pouca atenção que dava ao aluno. $\mathrm{O}$ mesmo ocorria com a professora de Educação
Especial, que sempre falava que não tinha tempo de trabalhar com Diego.

A situação não era diferente nas outras aulas. Nas aulas de Educação Artística que vivenciamos com a turma, Diego não interagia muito com a professora. Já nas aulas de Educação Física que pudemos acompanhar, ele não era escolhido para os times, nem recebia atenção do professor; raramente participava da aula.

Reiteradamente, Diego, no decorrer do ano, recortou imagens de revistas, encartes, entre outros impressos, para colá-las em seu caderno na expectativa de posteriormente nomeá-las; copiou letras e números em livros de atividades; fez atividades em cartilhas para alfabetização. Não só as atividades, mas sua rotina ao chegar à sala de aula era sempre a mesma: juntava duas carteiras para organizar seu material; varria o chão embaixo delas, bem como seu entorno; pegava as revistas e os encartes no armário da professora; tirava seu caderno e seu estojo da mochila; e começava a trabalhar. Diego não gostava quando algum outro aluno invadia seu espaço.

Diego se isola [é isolado] da turma. No período da pesquisa, poucas vezes vivenciamos o aluno em interação com os outros alunos, embora perguntasse a todo tempo quem eram seus amigos. Dos registros em vídeo, trazemos algumas falas de Diego: em um dia na sala de aula chegou a questionar a uma pesquisadora, quando ela disse para ele ficar com seus amigos [referindo-se aos pares de sua turma], dizendo: "Amigo? Eu?; e, quando indagou à pesquisadora: $O$ que ele é meu? Amigo? [apontando para os alunos da turma]" (Registro diário de campo).

Poucas vezes vimos Diego se aproximar dos outros alunos, como em um dia, em que pegou seu caderno de desenho e se sentou no fundo da sala, próximo a um grupo de alunos que, costumeiramente, ficava fazendo desenhos em seus cadernos entre uma atividade e outra. Ou mesmo em um dia em que ele fazia a mesma atividade proposta para toda a classe e, ao terminar, foi de mesa em mesa mostrando aos outros alunos seu desenho de meia borboleta, completado por um recorte de revista.

Raras vezes vimos os alunos se aproximarem dele. Não raro, também, vivenciamos situações nas quais seus pares debochavam de sua forma de falar. Como no dia em que uma aluna debochou de sua fala, repetindo em voz alta para outro colega o que ela havia acabado de dizer para a pesquisadora. Por essas situações que ele vivenciava, ele sempre nos questionava: “Eu, tonto?” (Registro diário de campo). 
Não obstante, trazemos um outro episódio ocorrido no mesmo dia do trecho da aula trazido para análise, enquanto ele ainda estava sentado na mesa defronte a porta da biblioteca, com alunos do $1^{\circ}$ ano, que estavam em horário de recreio. Nesse tempo, uma outra aluna, também do $1^{\circ}$ ano, vendo Diego fora de sala de aula com seu material, se aproximou e indagou a pesquisadora:

00:04:25 - Aluna: Ele é doente?

00:04:27 - Pesquisadora: Ele é doente?... Por que você acha que ele é doente? Me conta [...]

00:04:50 - Pesquisadora: Mas, conta, por que você fez essa pergunta?

00:04:52 - Aluna, bem baixinho: "Num" sei!

(Áudio T5A 01, 7.4.2009)

Torna-se contundente, então, trazer para a problematização que, desde a avaliação pedagógica do ano 2006, entrada do aluno na escola, a professora registrou em sua ficha de avaliação que: "na interação com seus pares, é egoísta com seus amigos". Em outro documento, o de 2007, são destacados os impedimentos de Diego em se relacionar com seus pares, em razão de sua dificuldade em falar. Já no de 2008, outra professora descreve no relatório: "O aluno pouco interage com os alunos da sala, mostra-se disperso."

Há um estranhamento com relação a ele que se mostra nos relatos e nas avaliações das professoras, que o caracterizam como aluno "problema", e que se evidencia na pergunta da aluna do 1ํ ano: "Ele é doente?" Bem como, no questionamento do próprio aluno, "Eu, tonto?" (Registro diário de campo).

Essas situações nos fazem problematizar as condições de desenvolvimento do lugar que o aluno foi ocupando nessas práticas, ao longo dos anos no contexto da escolar. Lugar que faz Diego tanto indagar: "Eu, tonto?", como sair da sala buscando desempenhar o lugar por ele idealizado e desejado do ser aluno que executa a lição.

\section{Discussão dos episódios analíticos}

A indagação de Diego "Eu tonto?", parece estar articulada aos mesmos dispositivos que permitem que a imagem de Diego estudando do lado de fora da sala, somada ao lugar que ele foi ocupando nas relações na escola, dê elementos para a interpretação e indagação da aluna "Ele é doente?". Assim, a partir da ideia do julgamento pelo outro (significação) e do aspecto (est)ético do corpo, apoiadas por Bakhtin (1920-1930/2003), apontamos que Diego, na situação citada, é olhado e indagado sobre as suas (im)possibilidades de atuação social, em face do que foi sendo postulado sobre ser um corpo com deficiência ao longo da história: das marcas de impureza, de uma alma má, da obscuridade, do pecado, da razão médica, da doença, do feio, do torto, do disforme, do ser improdutivo, do que necessita ser reabilitado e normalizado (SILVA, 1986; CARMO, 1994; SOUZA, 2001).

Contudo, é interessante destacar, quanto a essa construção, incorporação, apropriação coletiva do lugar de Diego, que o aluno não tem marcas corporais, lesões ou malformações que indiquem qualquer doença. $\mathrm{O}$ lugar que ele foi ocupando ao longo de sua história nessa instituição escolar, somado ao que se mostra ou se explicita nele - em seu corpo, jeito, gesto, comportamento, atitude, fala -, provoca as indagações. Tal fato, ainda os escritos de Bakhtin (1920-1930/2003), nos levam a reflexão de como o olhar do outro, possível nas relações sociais vivenciadas, nos afeta. E, ainda que o ato de contemplar outro sujeito é ir além do estético, é um ato ético de julgar seu corpo, suas marcas, seus gestos, suas posturas, suas atitudes (TEZZA, 1997; AMORIM, 2006). Ou, ainda, para Bourdieu (1962/2006, p. 83), é adentrar o terreno "da consciência incorporada que os homens adquirem de sua posição social”.

A consciência incorporada, para Bourdieu, é o habitus corporal. Para Bourdieu (1976/2003, 1986/2004, 2005, 1979/2011), o habitus, em seu enfoque materialista, é o primado da razão prática, é produto de um trabalho social, é a natureza humana socialmente construída, é um capital. Diz respeito à capacidade criadora humana, às disposições adquiridas por experiência e incorporadas, quase postural, pois se inscreve na natureza biológica do corpo, posto que é uma lei social.

Ainda para esse autor, o corpo é um produto social, no qual o habitus pode ser perpetuado para além de suas condições sociais de produção, pois as propriedades corporais são constituídas por diversas mediações, como "as condições de trabalho (com as deformações, doenças, possíveis mutilações), as práticas de consumo, as dimensões do gosto" (BOURDIEU, 1977, p. 51). Isso posto, ele afirma que o corpo não fala somente sobre sua posição social atual, mas sobre toda a sua trajetória, sua(s) história(s) individual. As marcas corporais, para Bourdieu, são indícios de uma fisionomia moral, socialmente caracterizada.

Porém, ainda para Bourdieu (1962/2006, p.86), o habitus corporal pode ser compreendido (modelos culturais, técnicas e sistema de atitudes 
corporais apropriadas pelo sujeito) "[...] naquilo que se vive como mais natural, aquilo sobre o que a ação consciente não tem controle". No qual a aparência é compreendida como um símbolo da condição econômica e social: "A hexis corporal é, antes de tudo, signum social" (BOURDIEU, 1962/2006, p.86) Essas ideias nos fazem pensar que as experiências de Diego, dos lugares que ele foi o ocupando na escola, foram se inscrevendo em seu corpo e, também, o fazendo indagar sobre as suas condições de apropriação do papel de aluno.

"Organismo e mundo encontram-se no signo" (VOLOCHINOV/BAKHTIN, 1929-1930/ 1995). Retomamos aqui a ideia de que o corpo é signo, pois depende do outro para dar significado a ele, porquanto emana sentidos e significados; corpo é signo e na medida em que vai sendo significado, passa a refletir e refratar uma realidade que vai além de si mesmo, de sua realidade material, realidade atrelada ao julgo de valores ideológicos; é uma arena de lutas sociais, pois traz em seus significados índices de valores contraditórios, enquanto se constitui na disputa de valores ideológicos.

Dessa forma, assumimos que o corpo, na qualidade de signo, vai se significando na linguagem, no signo. Sobre as características do signo, Smolka (2000) argumenta que todo signo é móvel na dinamicidade do mundo, é flexível, carregando em si as marcas históricas de sua existência/experiência, sempre dependendo do outro para sua leitura, interpretação e significação. Na dinâmica do mundo, nas relações interpessoais, corpos interagem afetando o outro e afetando-se.

Contudo, ao assumirmos que tanto as relações sociais, no caso aqui tratado as que ocorrem nas práticas escolares, quanto o corpo signo são arenas de lutas semióticas/simbólicas, afirmamos que, ao mesmo tempo que Diego nos indaga "Eu, tonto?", no próprio ato de indagar e não afirmar, somado ao ato de buscar um espaço para assumir o lugar de aluno, ele nos faz perceber que estar inserido nas práticas escolares também lhe permite apropriar-se da ideia construída do corpo escolarizado, do aluno, e que sustenta muitas das políticas formuladas e das práticas escolares estabelecidas na história da instituição escolar (FOUCAULT, 1979/1998; OLIVEIRA, 2006; SOARES, 1994, 1998, 1999, 2007).

Como vimos, Diego se coloca [é colocado] à margem da sala, das atividades realizadas. É nesse e desse lugar que encontra espaço para cumprir seu dever de aluno de 5ำ ano do Ensino Fundamental.

O corpo é signo, e o jeito de ser e o agir são a consciência incorporada. Não só Diego escapa da aula, mas escapa também da ideia do doente, do tonto. Constrói seu lugar a partir da imagem que tem do lugar que deve ocupar como aluno.

Tal análise é possível com base nos pressupostos de Vygotski (1929/2000; 1934/2010) de que o sujeito torna próprio o que antes estava posto nas relações (arena de luta dos opostos), e o que é apropriado é o que foi possível de ser significado do lugar que ele ocupa e de sua experiência/vivência. É nesse processo que ele vai tomando consciência de quem é e de suas formas de participação, no caso, no contexto escolar.

Ao problematizar os estudos de Vygotski sobre a experiência/vivência (perejivanie), Smolka (2006, p. 107) afirma que a "experiência é resultante daquilo que impacta e é compreendido, significado, pela pessoa. [...] Não existe experiência sem significação. [...] Falar de experiência é falar de corpo/sujeito afetado pelo outro/signo [...] É falar da vida impregnada de sentido".

Sobre o lugar que só o sujeito pode ocupar na construção do conhecimento sobre si, MarzanoParisoli (2004, p. 13) nos faz pensar nas posições assumidas no (in)acabamento estético quando aponta que há um lugar que só pertence ao sujeito, “[...] há uma espécie de conhecimento de nosso corpo que os outros jamais poderão saber, por conhecimento imediato e direto, o que se passa nos limites de nossa esfera de sensibilidade corporal". Assim, podemos considerar que o acabamento (est)ético - processo intermitente - ocorre na tensão entre ao menos dois pontos de vista (o eu e o outro), na experiência com o outro, no ato ético (TEZZA, 1997, AMORIM, 2006).

Nesse sentido, Smolka (2006, p. 103) ainda chama-nos a atenção "[...] à cotidianidade da vida, à singularidade, aos acontecimentos e aos saberes que a vida impõe a uma pessoa [...]", afirmando que a experiência vive na "dialeticidade" da experiência singular, subjetiva, de uma experiência universal, objetiva, entre o comum da experiência ou a experiência comum partilhada.

Segundo Vygotski (1925/1996a, p. 80), “[...] a experiência determina a consciência". Tal ideia é corroborada pelos escritos de Thompson (apud Smolka, 2006, p. 105) sobre o conceito de experiência gerada na vida material, no ser social que determina a consciência, os moldes de agir de uma época, seus valores e suas normas, constituindo a consciência afetiva e moral: a ideia de construir a consciência na medida em que se vivenciam as experiências da vida por meio delas e nelas.

Marcas culturais, atitudes individuais. No processo de subjetivação nas relações sociais, o 
sujeito vai incorporando os significados produzidos no contexto no qual as relações ocorrem. Em última instância, então, acontece que os significados produzidos nas relações sociais marcam os corpos/sujeitos, constituindo e redimensionando as funções psicológicas humanas, bem como suas possibilidades de expressão.

Assim, assumimos que Diego, ao vivenciar o ser aluno em uma escola regular, incorpora tanto as marcas do olhar est(ético) do outro sobre ele (ideia de exotopia bakhtiniana), que têm como base os modelos culturais (em termos de Bourdieu) do ser deficiente, como também as do ser aluno. Esses papéis sociais se tornam consciência incorporada (habitus corporal) em um mesmo sujeito, em Diego. Desse modo, no ato (responsável) de sair da sala, ele assume seu lugar de aluno (BAKHTIN, 19191921/2010; TEZZA, 1997; AMORIM, 2006, 2009; SOBRAL, 2005, 2009; BOURDIEU, 1976/2003, 1986/2004, 2005, 1979/2011).

Isso posto, consideramos que, de algum modo, desse lugar, imerso nas relações/práticas escolares (condições concretas da vida), Diego se apropria das contradições/tensões das ideias que constituem a Educação Inclusiva, pois, como afirma Smolka (2012, p. 38) ao problematizar a formação histórica da palavra, devemos tomar como base a

[...] compreensão dos múltiplos sentidos nela condensados, como um influxo de sentidos [...]. Não se trata, portanto, de traçar uma história da palavra, mas de apontar para uma história das ideias na palavra e nos seus usos, de ressaltar uma memória de práticas sociais, discursivas; referese àquilo que foi e que vem sendo forjado, ao mesmo tempo relembrado e esquecido, na dinâmica das práticas cotidianas. Nessa perspectiva, qualquer elaboração conceitual implica (trans)formação e movimento dialético que contém o velho e o novo, o velho no novo.

No âmago, então, da ideia da Educação Inclusiva estão marcas do entrelaçamento do que se nega [o lugar da pessoa com deficiência na história, marcado pelo estranhamento e pelas impossibilidades de atuação nas esferas sociais] e do que se propõe [o redimensionamento do lugar da pessoa com deficiência nas relações sociais, no processo de educação e produção, reivindicando seu protagonismo na participação das práticas sociais].

\section{Considerações}

A análise das condições de desenvolvimento de Diego, com base nos registros de situações de ensino e da dinâmica das relações sociais, circunstanciados no acontecimento de uma aula, deunos a visibilidade das profundas contradições que caracterizam tanto os princípios que sustentam as políticas de Educação Inclusiva inserida no âmbito das de Educação Básica como as diretrizes para sua efetivação no interior de uma escola pública de periferia em uma região metropolitana brasileira.

As condições de desenvolvimento de Diego nos fazem também problematizar as contradições constitutivas dos pressupostos que sustentam a educação inclusiva. Conforme descrito na análise, de um lado, Diego é posto, assume e se indaga sobre o lugar de doente e deficiente que ocupa nas relações escolares, tanto nas interpessoais como nas de ordem institucionais. Por outro, é possível, nos episódios analíticos da aula apresentada, ver os movimentos de Diego buscando lição, reforço e suporte. Essa busca por aprender, de algum modo, nos faz considerar que estar em uma escola regular e participar da dinâmica desta o fez se apropriar, incorporar e querer ocupar o lugar de aluno.

Do ponto de vista de nossa análise, ao considerarmos o traçado histórico do movimento de luta política pelos direitos da pessoa com deficiência e do lugar destas no âmbito das políticas educacionais brasileiras, somado à noção de construção histórica da consciência - como produto e processo da vida em sociedade; síntese dos sentidos e significados históricos e da singularidade da incorporação dos significados da experiência vivida por cada um; possível pelo/no signo - (VYGOTSKI, 1929/2000, 1933/1996b; VOLOCHINOV/BAKHTIN, 1929-1930/1995), vislumbramos nesse movimento de Diego, na incorporação do lugar de aluno, um ponto importante em termos de redimensionamento das formas de participação social da pessoa com deficiência no âmbito da instituição escolar.

Contudo, essa tensão que se mostra entre o conceito/a concepção e o aluno/as condições concretas nos leva ainda a problematizar o princípio amplamente divulgado de que o convívio social mais amplo da escola inclusiva propicia, por si só, o respeito à diversidade e a cooperação, no qual, partindo da ideia de relações sociais idílicas, fica implícito que o redimensionamento de (pré)conceitos está implicado simplesmente no ato de (con)viver. Reiteramos os estudos que há muito vêm contestando os pressupostos idealistas da Educação Inclusiva, por não considerarem a concretude do cotidiano escolar, ao trazermos na análise as tensões explicitadas. 
Por fim, um fato importante: ao final do ano, após ser retido no $5^{\circ}$ ano, Diego saiu da escola para frequentar uma instituição especializada, pois sua família considerou que lá seria um lugar mais adequado para ele. Esse movimento final de Diego e sua família nos faz pensar que para além da luta política travada sobre qual o local para matrícula do aluno com deficiência no processo de escolarização, há de se pensar em políticas que foquem nas práticas cotidianas escolares, na sala de aula. E assim, no faz assumir a necessidade de revisão da estrutura política e de financiamento da educação básica brasileira, radicalizando a educação enquanto um bem público.

Mesmo que a política vigente, assim como suas traduções, mereça avaliações e reformulações, a garantia da educação pública e gratuita sob a responsabilidade do Estado não pode ser destituída. Em especial nesse momento histórico de duros ataques à democracia brasileira e aos avanços na construção de políticas de enfretamento aos processos de exclusão de direitos, e frente ao não respeito às políticas de Estado, afirmamos, a partir das análises aqui explicitadas, o direito dos alunos com deficiência a escola regular.

\section{Notas}

1 Todos os nomes dos sujeitos da pesquisa são fictícios.

2 Conhecimento obtido a partir de uma avaliação diagnóstica realizada com parâmetros próprios pela rede de ensino.

$3 \mathrm{O}$ banco de dados físico dos registros da pesquisa de campo encontra-se arquivado no grupo de pesquisa.

4 Documento elaborado a partir de todos os documentos arquivados na escola sobre o aluno e com os recortes dos registros em videogravação e audiogravação do aluno ao longo do ano letivo.

\section{Referências}

AMORIM, M. Cronotopia e exotopia. In: BRAIT, B. (Org.). Bakhtin: outros conceitos- chaves. São Paulo: Contexto, 2006. p. 95-114.

. Para uma filosofia do ato: "válido e inserido no contexto". In: BRAIT, B. Bakhtin, dialogismo e polifonia. São Paulo: Contexto, 2009. p. 17-44.

BAKHTIN, M. Para uma filosofia do ato responsável (1919-1921). [Tradução Valdemir Miotello \& Carlos Alberto Faraco]. São Carlos: Pedro \&João Editores, 2010.

. O autor e a personagem na atividade estética (1920-1930). In:__. Estética da criação verbal. Tradução Paulo Bezerra. 4. ed. São Paulo: Martins Fontes, 2003. p. 3- 192.

BALL, S. J.; BOWE, R. Subject departments and the 'implementation' of Nacional Curriculum policy: an overview of the issues. Journal of Curriculum Studies, v. 24, n. 2, p. 97-115, 1992.

BALL, S. J. Education reform: a critical and poststructural approach. Buckingham: Open University Press, 1994.

Diretrizes políticas globais e relações políticas locais em educação. Currículo sem Fronteiras, v. 1, n. 2, pp. 99-116, Jul/Dez, 2001.

BOURDIEU, P. Remarques provisoires sur la perception sociale du corps. In:___ Actes de la recherche em sciences sociales. Paris, v. 14, p. 5154, abr., 1977.

Gosto de classe e estilos de vida (1976). In: ORTIZ, R. (Org.). A sociologia de Pierre Bourdieu. São Paulo: Olho d'água, 2003.p.73-111.

Fieldwork in philosophy (1986). In: . Coisas ditas. São Paulo: Brasiliense, 2004.p. 15-48.

. O poder simbólico. 8 ed. Rio de Janeiro: Bertrand Brasil, 2005.

. O camponês e seu corpo (1962). Revista Sociologia Política. Curitiba, v. 26, p. 83-92, jun, 2006.

. A distinção: crítica social do julgamento (1979). 2 ed. rev. Porto Alegre: Zouk, 2011.

BRASIL. Decreto n. 6.949, de 25 de agosto de 2009. Promulga a Convenção Internacional sobre os Direitos das Pessoas com Deficiência e seu Protocolo Facultativo, Diário Oficial da União. Brasília, 26 de agosto de 2009.

Decreto n. 7.611, de 17 de novembro de 2011. Dispõe sobre a educação especial, o 
atendimento educacional especializado e dá outras providências, Diário Oficial da União. Brasília, 18 de novembro de 2011.

Lei n. 13.005, de 25 de junho de 2014, Aprova o Plano Nacional de Educação - PNE e dá outras providências, Diário Oficial da União. Brasília, 26 de junho de 2014.

CARMO, A. A. Deficiência Física: a sociedade brasileira cria, recupera e discrimina. 3 ed. Brasília: Secretaria dos Desportos/PR, 1994.

CNE/CEB/BRASIL. Resolução Conselho Nacional de Educação / Câmara de Educação Básica n.4, de 2 outubro de 2009: Institui diretrizes operacionais para o Atendimento Educacional especializado na Educação Básica, modalidade Educação Especial. Diário Oficial da União. Brasília, 5 de outubro de 2009.

CHEPTULIN, A. A dialética materialista: categorias e leis da dialética. São Paulo: AlfaÔmega, 2004.

FOUCAULT, M. Microfísica do poder (1979). 13 ed. Rio de Janeiro: Graal, 1998.

FREITAS, M. T. A. A perspectiva sócio-histórica: uma visão humana da construção do conhecimento. In: FREITAS; M. T. A.; SOUZA, S. J.; KRAMER, $\mathrm{S}$ (org.). Ciências Humanas e pesquisa: leituras de Mikhail Bakhtin. São Paulo: Cortez, 2003. p.26-38..

GARCIA, R. M. C. Discursos políticos sobre a inclusão: questões para as políticas públicas de Educação Especial no Brasil. In: Reunião da ANPEd - GT 15- Educação Especial, Caxambu (MG), Anais da 27 Reunião da ANPEd. Caxambu (MG): ANPEd, 2004.

Política e gestão de educação especial nos anos 2000: a lógica gerencial. In: XXIV Simpósio Brasileiro de Política e Administração em Educação / III Congresso Interamericano de Política e Administração, Vitória, Anais do XXIV Simpósio ANPAE, Vitória: ANPAE, 2009.

JANNUZZI, G. M.; CAIADO, K. R.M. APAE: 1954 a 2011: algumas reflexões. Campinas: Autores Associados, 2013.

KASSAR, M. C. M. Percursos da constituição de uma política brasileira de Educação Especial Inclusiva. Revista Brasileira de Educação Especial. Marília (SP), v.17, p. 41-58, Mai.-Ago., 2011a.

Educação especial na perspectiva da Educação Inclusiva: desafios da implantação de uma política nacional. Educar em Revista, Curitiba, n. 41, p. 61-79, jul./set., 2011 b.

Educação Especial no Brasil:

desigualdades e desafios no reconhecimento da diversidade. Educação e Sociedade, Campinas, v. 33, n. 120, p. 833-849, jul./set., 2012.

LAPLANE, A. L. F. Notas para uma análise dos discursos sobre inclusão escolar. In: GÓES, M. C. R.; LAPLANE, A. L. F. (Org.) Políticas e práticas de educação inclusiva. Campinas: Autores Associados, 2004. p.5-20.

Contribuições para o debate sobre a

política de inclusão. In: LODI, A. C. B.; HARRISON, K. M. P.; CAMPOS, S. R. L. (Org.) Leitura e escrita: no contexto da diversidade. 2. ed. Porto Alegre: Mediação, 2006. p.27-32.

LAPLANE, A. L. F.; CAIADO, K. R. M.;

KASSAR, M. C. M. As relações público-privado na Educação Especial: tendências atuais no Brasil. Dossiê Observatórios de Educação Especial e Inclusão Escolar, Revista Teias, v. 17, n . 46, jul./set. p. 40-55, 2016.

MARZANO-PARISOLI, M. M. Pensar o corpo. Petrópolis (RJ): Vozes, 2004.

MENDES, E. G. A radicalização do debate sobre inclusão escolar no Brasil. Revista Brasileira de Educação, São Paulo, v. 11, n. 33, set./dez., 2006a.

. A pesquisa sobre a inclusão escolar no Brasil: será que estamos caminhando de fato na busca de soluções para os problemas. In: JESUS, D. M.; BAPTISTA, C. R.; VICTOR S. L. (Orgs.) Pesquisa e Educação Especial: mapeando produções. Vitória: EDUFES, 2006b. p.155-176.

PLESTCH, M. D. Repensando a inclusão escolar: diretrizes, práticas curriculares e deficiência intelectual. Rio de Janeiro: Nau/Edur, 2010.

PRIETO, R. G. Políticas públicas de inclusão: compromissos do poder público, da escola e dos 
professores. Revista de educação APEOSESP. São

Paulo, v. 1, n. 16, p. 23-28, mar, 2003.

. Sobre mecanismos de reprodução de sentidos das políticas educacionais. In: BAPTISTA, Cláudio R.; CAIADO, Kátia. M.; JESUS, Denise M (Orgs.). Educação Especial: dialogo e pluraridade. 2 ed. Porto Alegre: Mediação, 2010. P.25-33.

OLIVEIRA, M. A. T. (Org.) Educação do corpo na escola brasileira. Campinas: Autores Associados, 2006.

SECADI/MEC. Nota técnica No 62/ 2011/ MEC/ SECADI/ DPEE. Orientações aos Sistemas de Ensino sobre o Decreto $n^{\circ}$ 7.611/2011. Brasília: MEC/ SECADI, 2011.

. A consolidação da inclusão escolar no Brasil 2003 a 2016. Brasília: MEC/SECADI, 2016.

SEESP/MEC. Série Educação Inclusiva: Referências para Construção dos sistemas educacionais inclusivos. Brasília: MEC/SEESP, 2004.

Documento subsidiário à Política de Inclusão. Brasília: MEC/SEESP, 2005a.

Ensaios pedagógicos: construindo escolas inclusivas. Brasília: MEC/SEESP, 2005 b.

Programa Educação Inclusiva Direito a Diversidade: documento orientador. Brasília: MEC/SEESP, 2005c.

Ensaios pedagógicos. Brasília:

MEC/SEESP, 2006a.

Experiências educacionais inclusivas:

Programa de Educação Inclusiva: direito à diversidade. Brasília: MEC/SEESP, 2006b.

Educar na diversidade: material de formação docente. 3 ed. Brasília: MEC/SEESP, $2006 \mathrm{c}$.

Política Nacional de Educação Especial na Perspectiva da Educação Inclusiva. Brasília: MEC/SEESP, 2008.

Manual de acessibilidade espacial para escolas: o direito à escola acessível. Brasília:
MEC/SEESP, 2009.

SILVA, O. M. A epopeia ignorada: a pessoa deficiente na história do mundo de ontem e hoje. São Paulo: CEDAS, 1986.

SNPD/SDH/BRASIL. História do movimento político das pessoas com deficiência no Brasil, 2010.

SMOLKA, A. L. B. O (im)próprio e o (im)pertinente na apropriação das práticas sociais. Cadernos Cedes: relações de ensino: análises na perspectiva histórico-cultural. Campinas, n. 50, p. 26-40, 2000.

. Experiência e discurso como lugares de memória: a escola e a produção de lugares comuns. Pro-posições: Temas e tendências na perspectiva histórico-cultural. Campinas, v. 17, n. 2(50), p. 99118, mai./ago., 2006.

. Condições de desenvolvimento humano e de realização do trabalho na escola: relações de ensino e coletivos de trabalho. Campinas, 2012. Tese de Livre Docência em Educação (Psicologia Educacional), Universidade Estadual de Campinas.

SOARES, C. L. Educação Física: raízes europeias e Brasil. Campinas: Autores Associados, 1994.

Imagens da educação no corpo. Campinas: Autores Associados, 1998.

Apresentação. Cadernos Cedes 48: Corpo e Educação. Campinas: CEDES, 1999.p.5-6.

. (Org.). Pesquisas sobre o corpo: ciências

humanas e educação. Campinas: Autores

Associados; São Paulo: FAPESP, 2007.

SOBRAL, A. Ato/atividade e evento. In: BRAIT, B. Bakhtin: conceitos chaves. São Paulo: Contexto, 2005. p. 11-36.

O conceito de ato ético de Bakhtin e a responsabilidade moral do sujeito. BIOETHIKOS. São Paulo: Centro Universitário São Camilo, v. 3(1), p.121-126, 2009.

SOUZA, F. F. O corpo dança: con(tra)dições e possibilidades de sujeitos afásicos. Campinas, 2001. Dissertação de Mestrado em Educação (Educação, 
Conhecimento, Linguagem e Arte), Universidade Estadual de Campinas.

Políticas de educação inclusiva: análise das condições de desenvolvimento dos alunos com deficiência na instituição escolar. Campinas, 2013. Tese de Doutorado, em Educação (Psicologia Educacional), Universidade Estadual de Campinas.

As pessoas com deficiência e a educação: políticas sociais e de educação inclusiva nos governos do PT (2003 - 2011). Agenda Social (UENF), v. 10, p. 1-16, 2017.

TEZZA, C. A construção das vozes no romance. In: BRAIT, B. Bakhtin, dialogismo e construção do sentido. Campinas: Editora da Unicamp, 1997.p. 219-226.

VYGOTSKI, L. S. Génesis de las funciones psíquicas superiores. História del desarrollo de las funciones psíquicas superiores (1931). In: Obras Escogidas III. Madri: Visor, 1995. P.139-168. A consciência como problema da psicologia do comportamento (1925). In: Teoria e método em psicologia. São Paulo: Martins Fontes, 1996a. p.55-85.

. O problema da consciência (1933). In: . Teoria e método em psicologia. São Paulo: Martins Fontes, 1996b. p.171-189.

. Manuscrito de 1929 (1929). Educação e Sociedade, Campinas, Cedes, ano XXI, n. 71, p. 2144, 2000.

. Quarta aula: a questão do meio na pedologia, Lev Semionovich Vygotski (1934). Tradução Márcia Pileggi Vinha \& Max Welcman. Psicologia USP [online]. 2010, vol. 21, n. 4, pp. 681-701. ISSN 0103-6564. Disponível em: $<\mathrm{http}: / /$ dx.doi.org/10.1590/S010365642010000400003>. Acesso em 15 de setembro de 2012.

VOLOCHINOV/BAKHTIN, M. Marxismo e Filosofia da Linguagem (1929-1930). 7. ed. São Paulo: HUCITEC, 1995.

\section{Sobre a autora:}

Flávia Faissal de Souza é Licenciada em Educação Física (UERJ), mestre e doutora em Educação (FE/Unicamp) e pós-doutora em Educação (UFRRJ). Professora Adjunta da Faculdade de Educação da Baixada Fluminense (FEBF/UERJ), do Programa de Pós-Graduação em Educação, Cultura e Comunicação em Periferias Urbanas (PPGECC/FEBF/UERJ) e do Programa de Pós-graduação em Educação (ProPEd/EDU/UERJ).

Recebido em julho de 2018.

Aprovado em outubro de 2018. 